Article

\title{
Polyvinylidene Fluoride-Graphene Oxide Membranes for Dye Removal under Visible Light Irradiation
}

\author{
Sabri Alyarnezhad ${ }^{1}{ }^{(0)}$, Tiziana Marino ${ }^{2, *}$, Jalal Basiri Parsa ${ }^{1}$, Francesco Galiano ${ }^{2}{ }^{\circledR}$, \\ Claudia Ursino $^{2}$, Hermenegildo Garcìa ${ }^{3}$, , Marta Puche $^{3(1)}$ and Alberto Figoli ${ }^{2, *(1)}$ \\ 1 Department of Applied Chemistry, Faculty of Chemistry, Bu-Ali Sina University, Hamedan 65174, Iran; \\ sabri_alyarnezhad@yahoo.com (S.A.); parssa@basu.ac.ir (J.B.P.) \\ 2 Institute on Membrane Technology, CNR-ITM, Via P. Bucci 17c, 87030 Rende (CS), Italy; \\ f.galiano@itm.cnr.it (F.G.); c.ursino@itm.cnr.it (C.U.) \\ 3 Instituto Universitario de Tecnología Química (CSIC-UPV), Universidad Politecnica de Valencia, \\ AV. de los Naranjos s/n, 46022 Valencia, Spain; hgarcia@qim.upv.es (H.G.); mpuche@itq.upv.es (M.P.) \\ * Correspondence: t.marino@itm.cnr.it (T.M.); a.figoli@itm.cnr.it (A.F.); Tel.: +39-0984-49-2027 (A.F.)
}

Received: 26 May 2020; Accepted: 6 July 2020; Published: 7 July 2020

\begin{abstract}
In this study, polyvinylidene fluoride (PVDF)-graphene oxide (GO) membranes were obtained by employing triethyl phosphate (TEP) as a solvent. GO nanosheets were prepared and characterized in terms of scanning and transmission electron microscopy (SEM and TEM, respectively), atomic force microscopy (AFM), X-ray photoelectron spectroscopy (XPS), chemical analysis and inductively coupled plasma mass spectroscopy (ICP). Two different phase inversion techniques, Non-Solvent Induced Phase Separation (NIPS) and Vapour-Induced Phase Separation (VIPS)/NIPS, were applied to study the effect of fabrication procedure on the membrane structure and properties. Membranes were characterized by SEM, AFM, pore size, porosity, contact angle and mechanical tests, and finally tested for photocatalytic methylene blue $\left(\mathrm{MB}^{+}\right)$degradation under visible light irradiation. The effect of different $\mathrm{pH}$ values of dye aqueous solutions on the photocatalytic efficiency was investigated. Finally, the influence of $\mathrm{NaCl}$ salt on the $\mathrm{MB}+$ photodegradation process was also evaluated.
\end{abstract}

Keywords: PVDF-GO membranes; photocatalytic membranes; triethyl phosphate; GO nanosheets; dye removal; photocatalysis

\section{Introduction}

The shortage of fresh water and increasing industrial discharge from human activities are the most critical concerns in industrialized cities. In this framework, several processes oriented to the treatment and reuse of wastewaters and seawater such as membrane bioreactors (MBRs) [1], membrane distillation [2], solar to steam generation systems [3-5] are undergoing rapid expansion.

One of the most important sources of water contamination is the textile wastewater that includes a variety of organic dyes, which should not be underestimated because of their poisonousness, carcinogenic potential and non-biodegradability. From this perspective, effective wastewater treatment technologies with minimum consumption of energy and reagents for chemical conversion of organic dyes into safe (non-toxic) or harmless compounds are required [6]. Photocatalytic membranes, including inorganic [7-11] and polymeric membranes [12,13] under UV [9,14-18], visible [19] and UV-visible $[8,20,21]$ irradiations have been studied. Because of its harmfulness and high-energy consumption, UV irradiation is undesirable. Being ecofriendly and natural, visible light has shown great potential for energy-efficient water purification. In fact, only $4-7 \%$ of the solar spectrum is UV 
and $47 \%$ of that is visible light irradiation [8]. Moreover, the majority of polymeric membranes cannot tolerate UV light for long irradiation times, hence expensive ceramic membranes should be preferred, with an increase in capital costs [22]. Coupling visible-light photocatalysis and membrane separation technology in a single stage could simplify the water treatment process in accordance with the strategy of Process Intensification [23]. Membrane technology has been used due to its high selectivity, easy control, operation and scale-up, low environmental impact and low energy consumption. However, the use of volatile and toxic organic solvents, such as $\mathrm{N}$-methyl-2-pyrrolidone (NMP), N,N-dimethylformamide (DMF) and $\mathrm{N}, \mathrm{N}$-dimethylacetamide (DMA) which represent the major components during the phase inversion procedure, does not allow most of the current membrane production processes to be defined as "green". On the contrary, triethyl phosphate (TEP), being completely miscible with water and possessing a high boiling point $\left(215^{\circ} \mathrm{C}\right)$, represents a non-toxic solvent, already studied for polyvinylidene fluoride (PVDF) membrane fabrication in safer operational conditions [21,24,25]. The proper TEP solvency power towards PVDF is also confirmed by thermodynamic factors, that is, Hansen solubility parameters, which clearly evidence that homogeneous PVDF-TEP solutions can be easily obtained [26]. PVDF, with repeated - $\left(\mathrm{CH}_{2} \mathrm{CF}_{2}\right)_{n}$ - units, manifests excellent chemical and mechanical resistance, combined with a good thermal stability, which makes it one of the most preferred materials for membrane fabrication. The use of semiconductor photocatalysts and their blends, such as $\mathrm{TiO}_{2}$ [25], $\mathrm{TiO}_{2} / \mathrm{SiO}_{2}[27,28], \mathrm{TiO}_{2} / \mathrm{RGO}[29], \mathrm{TiO}_{2} / \mathrm{GO}[17,18]$ and $\mathrm{g}-\mathrm{C}_{3} \mathrm{~N}_{4} / \mathrm{RGO}$ [19], in the fabrication of photoactive membranes, has attracted considerable interest in recent years. In addition, mainly due to the possibility of being excited by visible light, ideally by using solar light, some of these photocatalysts are able to degrade pollutants as well as to provide antifouling properties due to the presence of high densities of oxygen groups on the photocatalyst particles. Table 1 presents a list of studies related to photocatalytic processes for contaminants' abatement in membrane technology.

Table 1. Membranes containing photocatalysts for pollutants' degradation.

\begin{tabular}{|c|c|c|c|c|c|}
\hline Membrane & Photocatalyst & Immobilization Method & $\begin{array}{l}\text { Irradiation } \\
\text { Wavelength }\end{array}$ & $\begin{array}{l}\text { Pollutant Removal } \\
\text { Studied }\end{array}$ & Reference \\
\hline Ceramic & $\mathrm{GO}$ and $\mathrm{TiO}_{2}$ & Dip-coating technique & UV and visible light & $\begin{array}{l}\text { Methyl orange and } \\
\mathrm{MB}^{+}\end{array}$ & [29] \\
\hline Polysulfone & $\mathrm{GO}$ and $\mathrm{TiO}_{2}$ & Layer-by-layer assembly & UV and Sunlight & $\mathrm{MB}^{+}$ & [18] \\
\hline Ceramic & $\mathrm{GO}$ and $\mathrm{TiO}_{2}$ & Dip coating method & UV and visible light & Azo dye pollutants & [8] \\
\hline Cellulose & $\mathrm{TiO}_{2}$ and $\mathrm{GO} \& \mathrm{TiO}_{2}$ & $\begin{array}{l}\text { Assembling the nano particle on } \\
\text { the flat sheet membrane }\end{array}$ & UV and visible light & $\begin{array}{l}\text { diphenhydramine, } \\
\text { methyl orange }\end{array}$ & [6] \\
\hline $\mathrm{Fe}_{2} \mathrm{O}_{3} / \mathrm{TiO}_{2} / \mathrm{GO}$ & $\mathrm{Fe}_{2} \mathrm{O}_{3} / \mathrm{TiO}_{2} / \mathrm{GO}$ composite & $\begin{array}{l}\text { Composite blending in } \\
\text { inorganic membrane }\end{array}$ & Solar irradiation & Humic acid & [30] \\
\hline PVDF & $\mathrm{GO}$ and $\mathrm{TiO}_{2}$ & Blending solutions & UV light & Bovine serum albumin & [17] \\
\hline $\begin{array}{l}\text { Cellulose } \\
\text { acetate }\end{array}$ & $\mathrm{g}-\mathrm{C}_{3} \mathrm{~N}_{4} \mathrm{NS}$ and RGO & $\begin{array}{l}\text { Assembly of nano composite on } \\
\text { the commercial membrane }\end{array}$ & Visible light & Rhodamine B & [19] \\
\hline Polysulfone & $\mathrm{N}-\mathrm{TiO}_{2}$ and $\mathrm{GO}$ & $\begin{array}{l}\text { grafted onto the membrane } \\
\text { surface using a pump filter }\end{array}$ & UV and Sunlight & $\mathrm{MB}^{+}$ & [31] \\
\hline
\end{tabular}

Different procedures have been applied for introducing the photocatalyst either on the membrane surface or inside the matrix. These methods mainly include dip coating, photochemical method [32] layer-by-layer assembly [33,34], physical deposition [35], phase inversion [35], biaxial stretching [36], plasma reduction [37]. The immobilization of nanoparticles on the membrane top surface, although offering the possibility to improve photocatalyst performance due to the presence of active sites on the membrane surface, could result in the leaching of photocatalyst nanoparticles during operation $[17,38]$. In contrast, the preparation of microfiltration (MF)/ultrafiltration (UF) membranes by polymer-photocatalyst blending and subsequent casting of the suspension, although less employed, is more adequate for better anchoring the nanoparticles inside the polymeric matrix and for conferring anti-fouling properties to the membrane [39-42].

Photocatalysts of nanometric dimension are better choices compared to the traditional large particle size semiconductors [43]. Because of their superior properties, including noticeable thermal stability, high mechanical strength and huge surface interaction, carbon-based nanomaterials are extensively studied [44-48]. Graphene oxide (GO) offers the possibility of the covalent anchoring of organic compounds because of its abundant epoxy and hydroxyl groups located on the basal plane 
and carboxyl and carbonyl groups placed on the edges of the flat sheets [49,50]. In photocatalysis, GO has attracted great attention due to its easy synthesis, structure and the presence of various functional groups [51,52]. The photocatalytic activity of GO nanostructures was investigated by Krishnamoorthy et al. [53] for the photoreduction in resazurin into resorufin as a function of time under UV irradiation. Hou and Wang [54] reported the use of GO as metal-free photocatalyst producing millimolar levels of $\mathrm{H}_{2} \mathrm{O}_{2}$ under visible light irradiation. The photocatalytic activity of GO derives from its semiconductor behavior with an absorption band at about $280 \mathrm{~nm}$, extending near the visible region. The activity of GO has been found to grow with its oxygen content.

In the present work, we reported the preparation of organic-inorganic polymeric membranes for environmental applications. The sustainability of the investigated techniques is given by the use of TEP as non-toxic solvents for the membrane preparation together with the visible light photocatalytic degradation of an organic dye for membrane applications.

GO was synthesized by modified Hummers method [51] while membranes were prepared via Non-Solvent Induced Phase Separation (NIPS) and Vapour-Induced Phase Separation (VIPS)/NIPS.

The photocatalytic performance of PVDF-GO membranes was examined for the degradation of methylene blue $\left(\mathrm{MB}^{+}\right)$under visible light irradiation $(\lambda>420 \mathrm{~nm})$. The effect of $\mathrm{pH}$ and the presence of sodium chloride in the dye aqueous solution were also investigated.

\section{Materials and Methods}

\subsection{Materials}

PVDF (Solef 6010) was purchased from Solvay Specialty Polymers S.p.A. (Bollate, Italy), polyethylene glycol (PEG, $M_{\mathrm{w}}=200 \mathrm{~g} \cdot \mathrm{mol}^{-1}$ ) from Sigma-Aldrich now Merck (Milan, Italy) and polyvinyl pyrrolidone (PVP, $M_{\mathrm{W}}=9000 \mathrm{~g} \cdot \mathrm{mol}^{-1}$ ) from Basf (Mannheim, Germany) were used as pore former additives. Graphite (synthetic fine powder, particle size $>20$ microns from Sigma-Aldrich), $\mathrm{H}_{2} \mathrm{SO}_{4}(98 \%), \mathrm{KMnO}_{4}(99 \%)$ and $\mathrm{H}_{2} \mathrm{O}_{2}$ (37\% aqueous solution) were purchased from Sigma Aldrich. TEP and $\mathrm{MB}^{+}\left(M_{\mathrm{W}}=373.9 \mathrm{~g} \cdot \mathrm{mol}^{-1}\right)$ were purchased from Sigma-Aldrich (Milan, Italy).

\subsection{GO Preparation and Characterization}

GO was prepared starting from graphite that was submitted to Hummers-Offeman oxidation followed by the exfoliation of resulting graphite oxide by sonication as described by Ruoff and coworkers [55]. Briefly, graphite powder $(3 \mathrm{~g})$ was dispersed in a mixture of concentrated $\mathrm{H}_{2} \mathrm{SO}_{4} / \mathrm{H}_{3} \mathrm{PO}_{4}$ $(360: 40 \mathrm{~mL})$ in an ice bath at $0{ }^{\circ} \mathrm{C} . \mathrm{KMnO}_{4}(18 \mathrm{~g})$ was carefully added to this suspension in small portions. A strong exothermic reaction raising the temperature to $35-40{ }^{\circ} \mathrm{C}$ was observed. CAUTION: $\mathrm{KMnO}_{4}$ addition has explosion risk! After total addition of $\mathrm{KMnO}_{4}$, the reaction mixture was then heated to $50{ }^{\circ} \mathrm{C}$ under stirring for $12 \mathrm{~h}$ to complete oxidation. Then, the reaction was cooled to room temperature and poured into $400 \mathrm{~g}$ of ice containing $30 \% \mathrm{H}_{2} \mathrm{O}_{2}(3 \mathrm{~mL})$ to decompose the excess of $\mathrm{KMnO}_{4}$. After air-cooling, the suspension was filtered, washed with 1:10 $\mathrm{HCl}(37 \%)$ solution and then with water. The resulting graphite oxide obtained in the oxidation was sonicated using a $700 \mathrm{~W}$ horn in $400 \mathrm{~mL}$ of water for $30 \mathrm{~min}$ and centrifuged at $4000 \mathrm{rpm}$ for $4 \mathrm{~h}$. The supernatant was centrifuged at $15,000 \mathrm{rpm}$ for $1 \mathrm{~h}$. The supernatant resulting after centrifugation at 15,000 rpm was collected and dried at $60^{\circ} \mathrm{C}$ to obtain GO.

The obtained GO was characterized in terms of ICP-optical emission spectroscopy (ICP-OES), transmission electron microscopy (TEM), atomic force microscopy (AFM), X-ray photoelectron spectroscopy (XPS) and infrared spectroscopy (FTIR), as described in the Supporting Information (SI).

\subsection{Membrane Preparation and Characterization}

Membranes were prepared using a combination of NIPS and VIPS methods [26,56]. PVDF casting solutions were prepared using TEP as a solvent with different weight ratios according to Table 2 . Three different types of membrane were studied. Dope solution containing just the polymer and the 
solvent was cast at different exposure times ( $0,2.5,5 \mathrm{~min})$ under controlled humid air $(\sim 55 \%)$ and temperature $\left(25^{\circ} \mathrm{C}\right)$ inside a climatic chamber (DeltaE S.r.l., Rende, Italy). The presence of additives, i.e., PVP and PEG, was also investigated. Finally, GO was incorporated in membranes exposed at different delayed times during the VIPS step. Table 2 summarizes the membranes produced by changing the operational conditions. For the preparation of photocatalytic membranes, first $\mathrm{GO}$ nanosheets were dispersed in TEP using an ultrasonic bath (USC600TH, VWR, Oud-Heverlee, Belgium) for $2 \mathrm{~h}$, then the additives and polymers were added and the dope solution was stirred at $100{ }^{\circ} \mathrm{C}$ for $12 \mathrm{~h}$ to ensure the formation of a homogeneous clear solution. Next, the solution was degassed for $6 \mathrm{~h}$ before casting. All dope solutions were cast on a glass plate $(20 \mathrm{~cm} \times 30 \mathrm{~cm})$ by using a manual film applicator set at $400 \mu \mathrm{m}$ (Elcometer 3700/1 Doctor Blade, Aalen, Germany; adjustable gap size: 30-4000 $\mu \mathrm{m}$ ). The membranes were washed with $60^{\circ} \mathrm{C}$ bidistilled water three consecutive times and then kept in bidistilled water for $12 \mathrm{~h}$ to remove residual solvents; then, the membranes were dried in air for $12 \mathrm{~h}$ and finally heated in an oven for $4 \mathrm{~h}$ at $50^{\circ} \mathrm{C}$.

Table 2. Dope solution components of the prepared membranes.

\begin{tabular}{ccccccc}
\hline Membrane CODE & PVDF (wt \%) & $\mathbf{P V P}_{\mathbf{K 1 7}}(\mathbf{w t} \%)$ & $\mathbf{P E G}_{\mathbf{2 0 0}}(\mathbf{w t} \%)$ & $\mathbf{T E P}(\mathbf{w t} \%)$ & $\mathbf{G O}(\mathbf{w t} \%)$ & $\begin{array}{c}\text { Exposure Time to Fixed Humidity } \\
\text { and Temperature (min) }\end{array}$ \\
\hline M1 & 13 & 0 & 0 & 87 & 0 & 0 \\
M2 & 13 & 0 & 0 & 87 & 0 & 2.5 \\
M3 & 13 & 0 & 0 & 87 & 0 & 5 \\
M4 & 13 & 3 & 24 & 60 & 0 & 2.5 \\
M5 & 13 & 3 & 24 & 60 & 0 & 5 \\
M6 & 13 & 3 & 24 & 60 & 0 & 0 \\
M7 & 13 & 3 & 24 & 59.875 & 0.125 & 2.5 \\
M8 & 13 & 3 & 24 & 59.875 & 0.125 & 5 \\
M9 & 13 & 3 & 24 & 59.875 & 0.125 & 0.5 \\
M10 & 13 & 3 & 24 & 59.5 & 0.5 & 2.5 \\
\hline
\end{tabular}

Membranes were characterized in terms of SEM, AFM, contact angle (CA), porosity, pore size, mechanical properties and pure water permeability (PWP) following the procedures described in the SI.

\subsection{Photocatalytic Degradation Test}

Photocatalytic performance of the membranes was tested by using $\mathrm{MB}^{+}$cationic dye as an organic contaminant with a molecular weight of $284 \mathrm{Da}$. Photocatalytic experiments were conducted by means of a cross flow cell with a quartz window on the top side, as shown in Figure 1. Before photocatalytic tests, in order to limit the phenomenon of adsorption, the membrane sample was conditioned overnight in a $50 \mathrm{~mL}$ dye solution $(10 \mu \mathrm{mol} / \mathrm{L})$. Photocatalytic experiments were performed by circulating $150 \mathrm{~mL}$ of a $10 \mu \mathrm{mol} / \mathrm{L} \mathrm{MB}^{+}$solution in both darkness and under visible light irradiation. Flow velocity and trans membrane pressure (TMP) were fixed at $1.5 \mathrm{~L} / \mathrm{h}$ and $0.2 \mathrm{MPa}$, respectively. The distance between a $150 \mathrm{~W}$ xenon lamp (E40 $4300 \mathrm{k} 220-240 \mathrm{~V} \mathrm{50-60} \mathrm{Hz)} \mathrm{and} \mathrm{cross} \mathrm{flow} \mathrm{cell} \mathrm{was} \mathrm{adjusted} \mathrm{at} 13 \mathrm{~cm}$. A cut-off UV irradiation filter (GG420 Colored Glass Filter, $420 \mathrm{~nm}$ long pass with $25 \mathrm{~mm}$ diameter FGL420, Thorlabs, Newton, NJ, USA) was employed to filtrate UV light wavelength. The wavelength range was between 400 and $1800 \mathrm{~nm}$. Irradiation was started after a preliminary stabilization time of the system (after $45 \mathrm{~min}$ recirculation of the solution) and, every $30 \mathrm{~min}, 1 \mathrm{~mL}$ of solution was taken from the feed tank. The concentration of $\mathrm{MB}^{+}$was measured using a UV/VIS spectrophotometer LAMBDA EZ 201, Perkin Elmer (city, country) at $664 \mathrm{~nm}$. The $\mathrm{MB}^{+}$solution was continuously run through the system so that the retentate and permeate were recirculated back inside the feed tank.

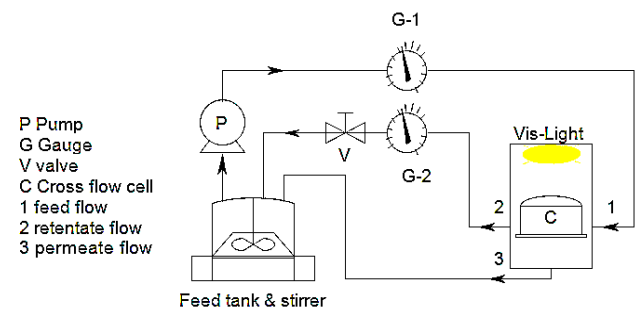

Figure 1. Schematic of photocatalytic cross flow system. 


\section{Results}

\subsection{Characterization of the GO Nanosheets}

GO was obtained by the deep chemical oxidation of graphite and exfoliation by sonication, as previously reported [55]. The resulting GO dispersion was centrifuged up to 15,000 rpm to remove those sediments that should correspond to incompletely exfoliated material. Only the supernatant resulting after high-speed centrifugation, that must be constituted by preferentially single-layer GO sheets of lateral size from 0.8 to 3.0 microns, was used in the present study. This was confirmed by AFM measurements (Figure $2 a, b$ ) of the GO suspended in aqueous medium. Analysis of a statistically relevant number of GO particles showed that most of them have a sheet thickness of $1.0 \mathrm{~nm}$, in the range of the expected values for hydrated single-layer GO [55]. TEM images showed wide fields full of GO nanosheets exhibiting a typical bidimensional morphology and lateral dimensions in the micrometer range with light contrast due to its single-layer configuration (Figure 2c).
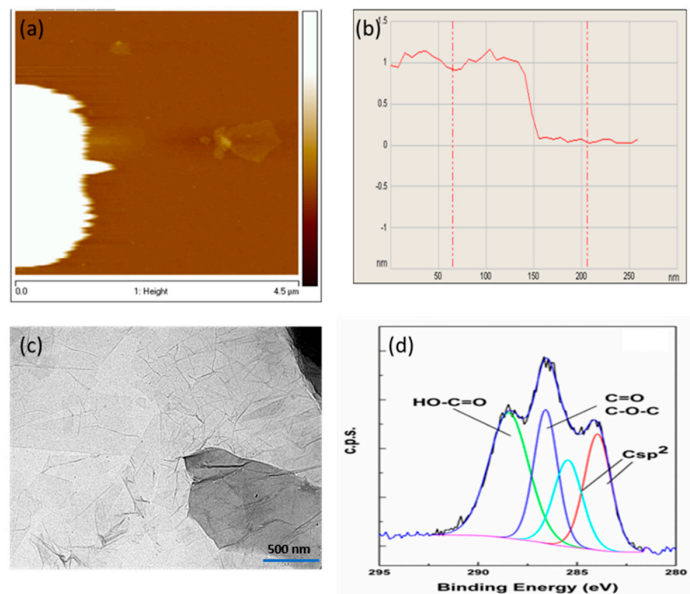

Figure 2. Exfoliated graphene oxide (GO) monolayer atomic force microscopy (AFM) image by non-contact mode (a) and vertical height of the sheet (b); (c) TEM image (scale bar $500 \mathrm{~nm}$ ); (d) Experimental, high-resolution XPS C1s peak of the GO employed in the present study and its best deconvolution fit to individual components.

GO was characterized by combustion chemical analysis, measuring a percentage of carbon slightly above 50\%. The presence of sulphur, probably associated with the presence of sulfonic and sulfate groups bonded to the GO sheets, was also determined in this analysis. Metal impurities, mainly manganese, were also detected by ICP-OES. Manganese was probably present as $\mathrm{Mn}^{2+}$ due to the chemical reduction in $\mathrm{MnO}_{4}{ }^{-}$by $\mathrm{H}_{2} \mathrm{O}_{2}$ and associated to carboxylate groups of $\mathrm{GO}$. SI file reports the Mn content of the samples under study. As already reported, IR spectroscopy of GO shows the presence of oxygenated functional groups, mainly carboxylic acids, hydroxyl and epoxy groups. The presence of oxygenated groups was also determined by XPS analyses (Figure $2 \mathrm{~d}$ ). It should be noted that, although XPS analysis can be carried out on GO powders, in the present case, XPS analysis was performed on thin films after depositing a drop of the GO aqueous suspension on quartz and allowing water to evaporate, before introducing the sample in the XPS machine. Both survey and high-resolution XP spectra showed an atomic carbon:oxygen ratio for the exposed GO surface of 1.7 based on the relative peak areas after correction by the response factor of each element (Figure S1 of SI). Deconvolution of the broad C1s peak in XPS fitted to four components corresponding to sp $\mathrm{p}^{2}$ carbons $(284.5 \mathrm{eV}, 22 \%)$, carbon atoms bonded to oxygen with single $(286 \mathrm{eV}, 18 \%)$ and double bond ( $287 \mathrm{eV}, 27 \%)$ and carboxylic acid groups (289.0 eV, 33\%). Figure $2 \mathrm{~d}$ shows the experimental high-resolution XPS C1s peak and its best deconvolution to the individual components. As shown in Raman spectrum (see Figure S2 of SI), in contrast to ideal graphene, where the shape and position of the $2 \mathrm{G}$ peak can be used to determine the number of layers, the broadness of the Raman peak at $2900 \mathrm{~cm}^{-1}$ in the case of rGO encompassing 
the $\mathrm{G}+\mathrm{D}$ and the $2 \mathrm{D}$ bands does not allow analogous analysis. In the case of GO, sub-nanometric AFM measurements are the safest technique to assess the single-layer nature of the GO sample used in the study. Overall, all the previous data are in agreement with those expected for a single-layer GO previously reported in the literature [55].

\subsection{Membrane Characterization}

SEM images of M1-M3 membranes, prepared with the polymer and the solvent at different exposure times, are presented in Figure 3.

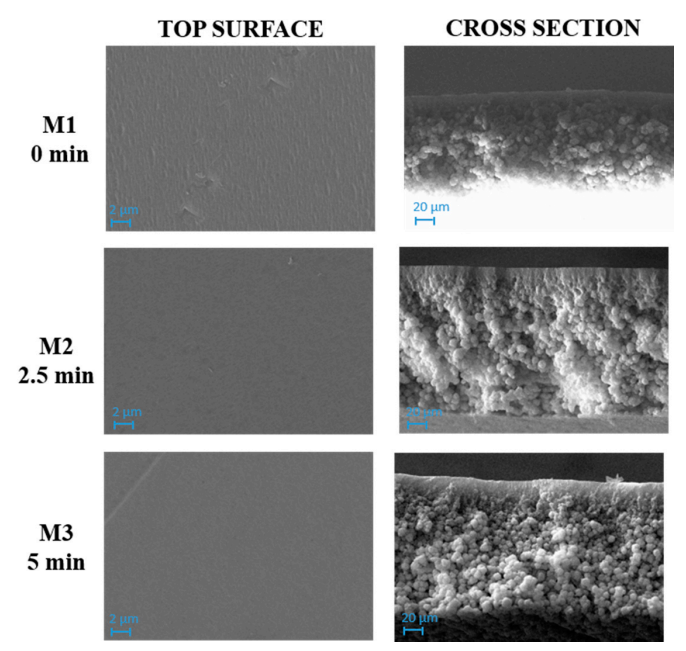

Figure 3. SEM images of M1, M2 and M3 membranes prepared with polyvinylidene fluoride (PVDF) and triethyl phosphate (TEP) and exposed for 0, 2.5 and 5 min to humidity, respectively. Magnification: top surface $10,000 \times$, cross section $1000 \times$.

SEM images evidenced a compact structure for M1, M2 and M3 membranes with no relevant differences between them. A dense layer on the top surface and a spherulitic matrix was formed for the three membranes. This observation could be explained by considering the high hydrophobicity of PVDF, which caused a fast demixing with the formation of a skin layer [57].

Figures 4 and 5 show SEM pictures of M4-M6 and M7-M9, respectively, in which both types of membranes were prepared by including PVP and PEG in the casting solution formulation.

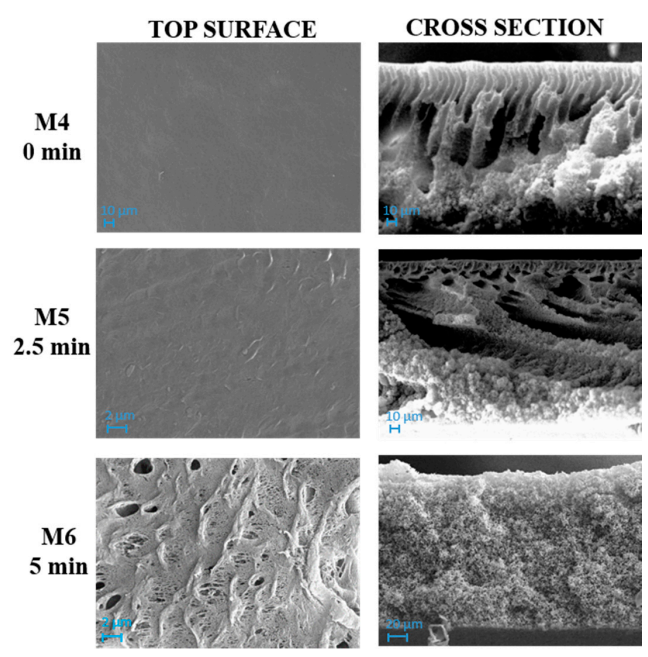

Figure 4. SEM images of M4, M5 and M6 membranes prepared with PVDF, PVP, PEG and TEP and exposed to humidity for $0,2.5$ and 5 min, respectively. Magnification: top surface 10,000×, cross section $1000 \times$. 
The influence of the NIPS/VIPS preparation procedure, during which the nascent films were exposed for different times to water vapour, was observed for both membrane types prepared with and without GO.

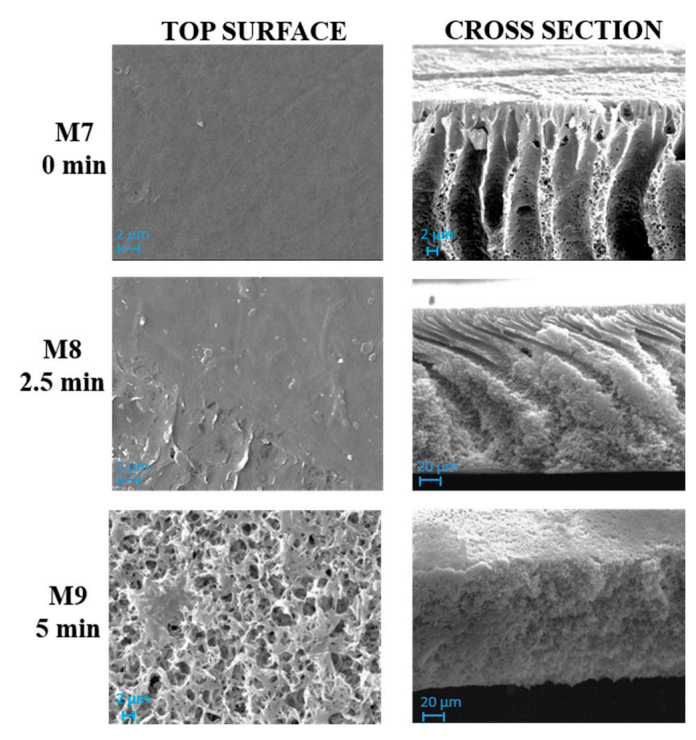

Figure 5. SEM images of M7, M8 and M9 membranes prepared with PVDF, PVP, PEG, GO and TEP and exposed to humidity for $0,2.5$ and $5 \mathrm{~min}$, respectively. Magnification: top surface $10,000 \times$, cross section $1000 \times$.

The solvent-non-solvent exchange rate represents one of the most affecting parameters during membrane formation. It is well known, for example, that the presence of water in vapour form during VIPS step, promotes a delayed demixing, thus favoring the formation of a more porous, sponge-like structure in comparison with NIPS process. However, it should be mentioned that, during polymer precipitation, kinetic factors also play a relevant role for the polymeric chains' arrangement. Thermodynamic factors are related to polymer precipitation behavior, while kinetic factors are related to the exchange rate of solvent/nonsolvent during phase separation [58]. The combination of the two factors results in different membrane structure and properties [59].

As can be seen in Figure 4, M4 membrane was significantly affected by the addition of pore-forming additives compared to the analogue M1 membrane formed from a PVDF-TEP solution. The M1 membrane showed a high compact structure, while M4 exhibited a finger-like structure on the top surface, surrounded by a cellular, porous layer. The presence of macrovoids across the entire cross section was observed for M7, which differed from M4 for the presence of GO.

The addition of additives dramatically increased the miscibility of solvent with non-solvent, therefore the creation of fingers and macrovoids was favored for M4 and M7. When the NIPS/VIPS method was adopted, the demixing rate between the solvent and the non-solvent was delayed, thus the presence of fingers and macrovoids gradually disappeared, with the formation of completely spongy membranes when the time interval reached 5 min [60]. The addition of PVP and PEG as pore-forming agents and GO nanosheets into the dope solutions increased the hydrophilicity of the dope solution. Due to its high solubility in water, PEG instantaneously dissolved in water during NIPS and left large macrovoids inside the membrane [61]. This analogy can be clearly observed in cross-section images of M1, M4, and M7 reported in Figures 3-5, respectively. The presence of PVP and PEG as pore-forming agents, together with GO, led to different morphologies, depending on the exposure time of the nascent film to water in vapour form. On the one hand, a porous matrix with macrovoids was observed when immersion-precipitation was adopted; in this case, the hydrophilic character of both additives and catalyst promoted a rapid TEP-water exchange. On the other hand, the increase in polymeric solution viscosity, due to the presence of PVP, PEG and GO as opposed to the mass transfer during phase 
inversion, led to a spongy matrix when the NIPS/VIPS procedure was followed and the nascent film was exposed to humid air for 5 min (Figure 5).

The exposure time to humidity (from 2.5 to $5 \mathrm{~min}$ ) greatly affected the morphology of the membranes prepared with additives (Figures 4 and 5). The exposure of the cast film to a humid environment promoted the formation of a more porous structure on the surface while, along the cross-section, it favored the formation a spongy architecture. The porogen effect of humidity is a quite well studied phenomenon and it is related to the adsorption, by the cast film, of water molecules from the humid air, which delays the phase-inversion process, fostering the creation of a porous and sponge-like structure [25,62-65].

Figure 6 presents the morphology of M10, i.e., the analogue M8 membrane (0.125 wt \% GO) prepared by increasing GO content $(0.5 \mathrm{wt} \%)$. The increase in GO concentration in the casting solution favored the increase in solution viscosity, thus delaying the demixing rate with the formation of a symmetric, sponge-like structure. The presence of GO nanosheets in the M8 and M10 can be clearly observed in the images provided in Figure 7 taken at a higher magnification.

TOP SURFACE

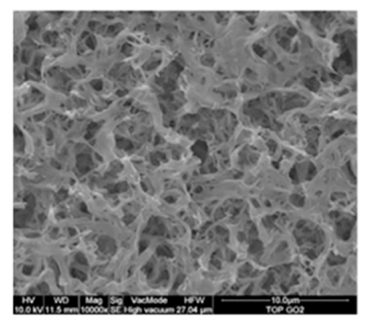

\section{CROSS SECTION}

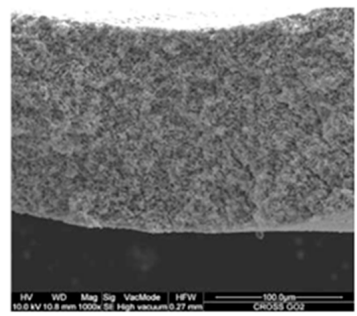

Figure 6. M10 SEM images. Magnification: top surface 10,000×, cross section 1000×.
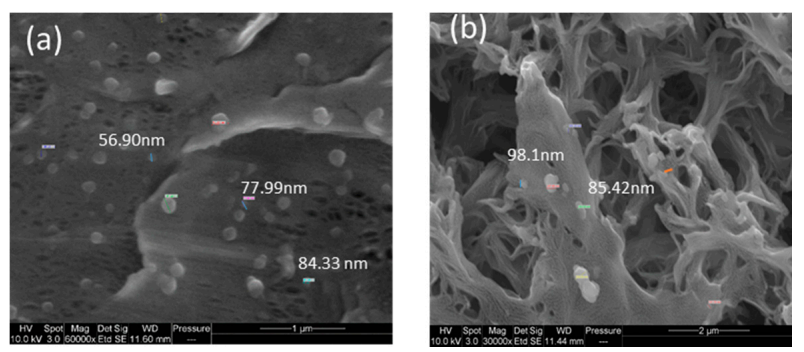

Figure 7. Images showing the presence of GO nanosheets: (a) M8 top surface (Magnification: 60,000x) and (b) M10 top surface (Magnification: 30,000×).

The effects of modification on the top surface morphology and roughness parameter of the fabricated membranes were also studied by AFM (Figure 8). The topography was measured on five different areas of the membrane surface and the root mean square (RMS) roughness (Sq), roughness average (Sa), and peak to peak value (Sz) were calculated. The obtained data and the respectively standard deviation are reported in Table 3.

Table 3. The roughness parameters of the membranes under study.

\begin{tabular}{cccc}
\hline \multirow{2}{*}{ Membrane } & Root Mean Square & Average Roughness & Mean Difference between Peaks and Valleys \\
\cline { 2 - 4 } & Sq $(\mathbf{n m})$ & Sa $(\mathbf{n m})$ & Sz $(\mathbf{n m})$ \\
\hline M1 & $21.01 \pm 0.21$ & $16.25 \pm 0.10$ & $165.09 \pm 25.94$ \\
M2 & $17.76 \pm 0.89$ & $13.23 \pm 0.62$ & $179.30 \pm 29.21$ \\
M3 & $11.89 \pm 0.22$ & $9.39 \pm 0.21$ & $125.50 \pm 17.73$ \\
M4 & $33.86 \pm 5.58$ & $26.33 \pm 3.82$ & $271.66 \pm 37.86$ \\
M5 & $33.25 \pm 1.53$ & $26.30 \pm 1.11$ & $281.84 \pm 44.83$ \\
M6 & $91.90 \pm 2.47$ & $70.12 \pm 0.84$ & $753.38 \pm 20.56$ \\
M7 & $34.10 \pm 6.33$ & $25.91 \pm 4.06$ & $224.01 \pm 30.01$ \\
M8 & $30.61 \pm 4.37$ & $25.04 \pm 3.22$ & $186.19 \pm 4.00$ \\
M9 & $43.41 \pm 15.69$ & $32.82 \pm 11.81$ & $267.75 \pm 3.39$ \\
M10 & $194 \pm 14.35$ & $146 \pm 10.15$ & $1465 \pm 30.80$ \\
\hline
\end{tabular}


Based on the extrapolated data and the series of images, it is possible to notice the following features:

- For membranes prepared with only polymer and solvent (M1, M2 and M3 membranes), the roughness decreased with increasing exposure time to humidity (0-2.5-5 $\mathrm{min})$. This result is in agreement with the SEM images (Figure 4) that show a dense skin layer on the top surface;

- For membranes obtained using PVP and PEG (M4, M5 and M6 membranes) as pore-forming agents, the roughness increased in relation to the humidity exposure time. In fact, these three membranes presented a more porous morphology, as already observed in the SEM images (Figure 5). In particular, the M6 membrane presented the highest roughness value;

- With respect to M4, M5 and M6 membranes, when GO nanosheets at $0.125 \mathrm{wt} \%$ were added to the dope solution (M7, M8 and M9 membranes), roughness value remained constant. The only exception was at the highest humidity exposure time of $5 \mathrm{~min}$ (M6 and M9 membranes), where the roughness (Sa) exhibited a decline from $70.12 \mathrm{~nm}$ (M6) to $32.82 \mathrm{~nm}$ (M9);

- Moreover, when the 0.5 wt \% of GO was used (M10 membrane), a membrane with higher roughness was observed. This result could be explained by the agglomeration of particles in the mixed-matrix membrane and the loss of uniformity due to the formation of more pores on the surface arising from the lower miscibility of the dope solution [66];

- In all cases, for all the membranes prepared with PVP and PEG, the average roughness was enhanced compared to M1-M3 membranes. Furthermore, M7-M9 membranes with higher cavities and pores on the surface possessed higher roughness that led to an increased permeability. The intensification of GO concentration in membranes generally exhibited higher roughness compared to those with lower concentrations (as in the case of M10).

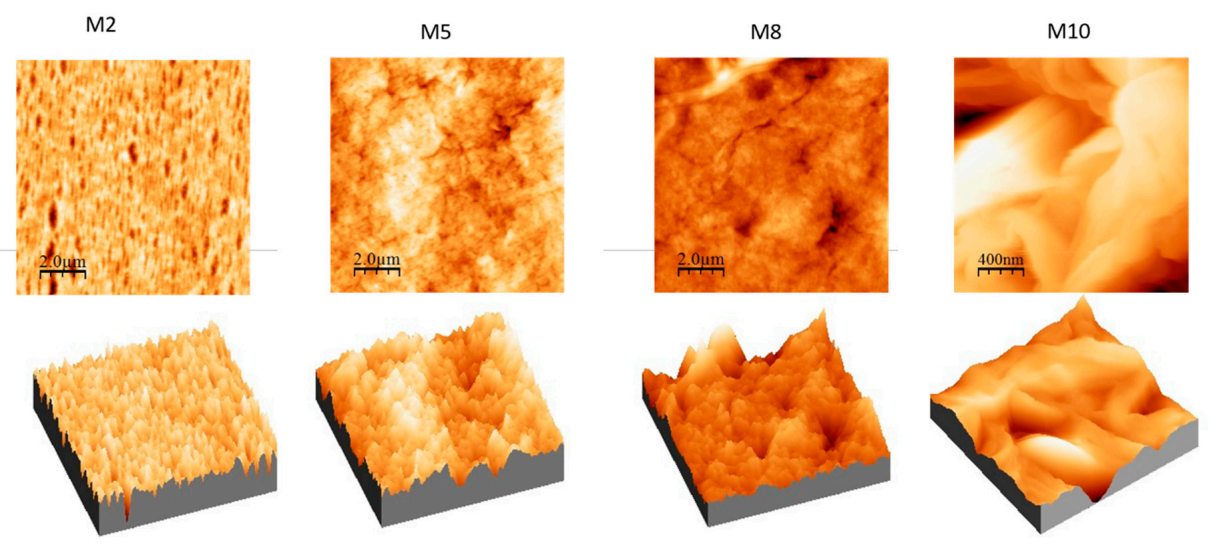

Figure 8. AFM images with corresponding 3D views of M2, M5, M8 and M10 membranes deriving from films exposed to humidity for 2.5 min during VIPS-NIPS.

For water treatment applications, membrane hydrophilicity, assuring water passage through membrane pores and reducing fouling, represents a key parameter.

Typically, to measure the hydrophilic properties of the membranes, CA is used. The values of CA for the membranes (top side and bottom side) are listed in Table 4. According to CA measurements (top sides), the hydrophilic character of M1-M3 membranes was independent from delay time as well as SEM, AFM and PWP characterization, and may be due to PVDF chains arrangement during phase inversion. The presence of hydrophilic pore-forming agents in the dope solution, i.e., PVP and PEG, led to the reduction in membrane CA for M4 (CA $65 \pm 2^{\circ}$ ) prepared via NIPS. However, by coupling NIPS with VIPS, more hydrophobic membranes were obtained, and the CA increased with the increase in exposure time to a controlled relative humidity from 2.5 to $5 \mathrm{~min}$. In fact, M5 showed a CA of $77 \pm 2^{\circ}$, while M6 had a CA of $108 \pm 3^{\circ}$. These results may be related to the membrane roughness, which increased concomitantly by extending the interval times during the VIPS step. Similar results were 
reported in the literature [67]. Decreased roughness means smoother surfaces for M7-M9 membranes, which in turn results in a decreased contact angle [68]. The increase in membrane hydrophilicity was due to the well-distributed GO nanosheets on the top surface of the membranes that attracted water molecules and created a thin shielding water layer on the pores [69]. This was at the basis of the very hydrophilic nature of M10 membrane prepared with the highest concentration of GO.

Table 4. Thickness and contact angle (CA) of the prepared membranes.

\begin{tabular}{cccc}
\hline \multirow{2}{*}{ Membrane } & Thickness $(\mu \mathrm{m})$ & \multicolumn{2}{c}{ CA } \\
\cline { 3 - 4 } & & Top Side $\left({ }^{\circ}\right)$ & Bottom Side $\left(^{\circ}\right)$ \\
\hline M1 & $121.4 \pm 1.7$ & $72 \pm 3$ & $102 \pm 2$ \\
M2 & $123.7 \pm 1.3$ & $71 \pm 3$ & $106 \pm 3$ \\
M3 & $132.5 \pm 1.5$ & $75 \pm 1$ & $112 \pm 2$ \\
M4 & $144.1 \pm 3.2$ & $65 \pm 2$ & $106 \pm 1$ \\
M5 & $159.0 \pm 5.5$ & $77 \pm 2$ & $117 \pm 2$ \\
M6 & $170.5 \pm 7.0$ & $108 \pm 3$ & $130 \pm 2$ \\
M7 & $158.6 \pm 1.2$ & $61 \pm 2$ & $100 \pm 3$ \\
M8 & $161.0 \pm 0.9$ & $68 \pm 2$ & $129 \pm 1$ \\
M9 & $163.4 \pm 1.4$ & $82 \pm 3$ & $125 \pm 3$ \\
M10 & $162.5 \pm 1.2$ & $63 \pm 3$ & $118 \pm 3$ \\
\hline
\end{tabular}

CA assessment for M7-M9 membranes revealed a positive effect of GO on membrane hydrophilicity. In fact, the incorporation of GO nanosheets in the polymeric matrix promoted the formation of oxygen functional groups (such as hydroxyl and carboxyl groups) on the top surface, increasing the hydrophilic membrane character. However, similarly to what has been observed for MB-type membranes, when the exposure time to water, in vapour form, passed from 0 to 2.5 , until $5 \mathrm{~min}$, the CA increased, due to the increase in membrane roughness [70]. Representative CA pictures of M1 and M7 membranes are reported in the SI (Figure S3).

The results obtained for the membrane pore size and PWP are reported in Figure 9. By increasing the time intervals during the VIPS step, M1-M3 membranes, having a pore diameter in the range between $\sim 0.06$ and $\sim 0.08 \mathrm{~m}$, were not significantly affected; in other words, the exposure time to relative humidity did not play a relevant role for membrane pore size determination. On the contrary, by varying the casting solution composition, evident changes in mean flow pore diameter were detected.

The addition of PVP and PEG, as shown and explained in SEM pictures, fostered the formation of a more porous structure, which resulted in membranes with a larger pore size and, therefore, a higher PWP.

M4 showed a pore size of $\sim 0.1 \mathrm{~m}$, increased up to $\sim 0.5 \mathrm{~m}$ for M5 and reached a value of $\sim 0.7 \mathrm{~m}$ for M6. Hence, the combination of a PVDF-TEP and PVP-PEG dope system, together with VIPS/NIPS preparation procedure, allowed for tailoring the membrane pore size. By adding GO to the dope solution, a decrease in the membrane pore size for M8 and M9 was noted. Although further investigations should be necessary to better understand the reduction in membrane pore size, a first explanation could be associated with the dope solution viscosity, which increased when GO nanosheets were added to the polymer-solvent-additives solution. Similar results are reported in the literature by Zhu et al. [71]. Furthermore, the competition between the solvent and the nano-fillers to exchange with the non-solvent caused a lower mean flow diameter. By using a higher GO concentration, i.e., $0.5 \mathrm{wt} \%$, the resulting M10 membrane exhibited a pore size in the MF range ( 0.35 m). The PWP results are presented in Figure 9. M1-M3 membranes showed no PWP up to three bars. The reason for this can be ascribed to a compaction phenomenon which may have occurred during membrane pressurization, which caused a constriction of the small pores, blocking the permeation of water. The analogue M4 and M7 membranes, on the contrary, resulting from solutions containing additives and GO-fillers, respectively, allowed water to pass across membrane pores. Specifically, M4 exhibited a PWP of $\sim 150 \mathrm{~L} \cdot \mathrm{m}^{-2} \mathrm{~h}^{-1} \mathrm{bar}^{-1}$, while M7 had a $\sim 110 \mathrm{~L} \cdot \mathrm{m}^{-2} \mathrm{~h}^{-1} \mathrm{bar}^{-1}$. For the membranes prepared via NIPS/VIPS, the PWP reflected the pore size results: PWP increased when the exposure time to 
non-solvent in vapour form passed from 2.5 to $5 \mathrm{~min}$. In general, the increase in exposure time to humidity promoted the formation of membranes with a larger pore size and higher PWP.

The best results in terms of PWP were obtained for M6 $\left(\sim 3400 \mathrm{~L} \cdot \mathrm{m}^{-2} \mathrm{~h}^{-1} \mathrm{bar}^{-1}\right)$, which had a mean flow pore diameter of $\sim 0.7 \mathrm{~m}$.

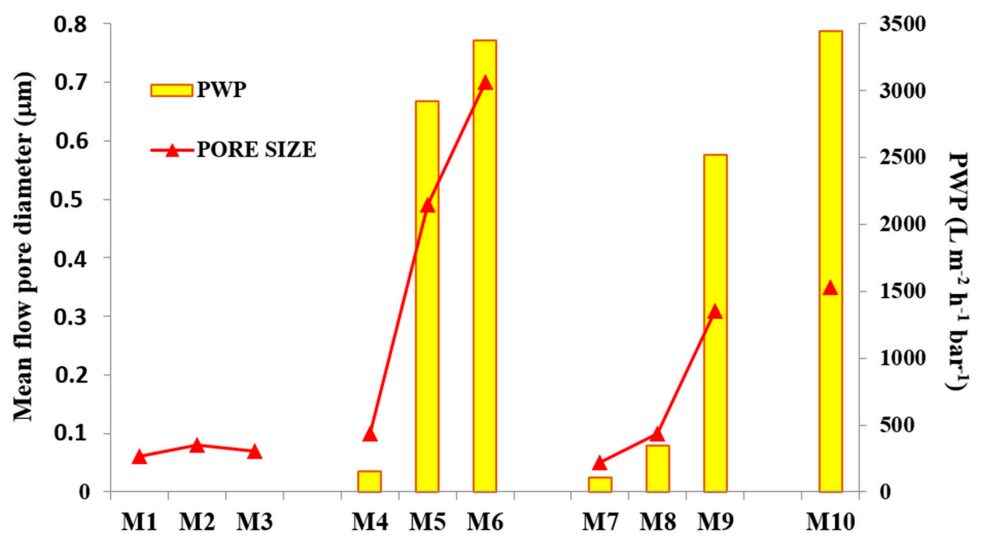

Figure 9. Pure water permeability (PWP) correlated with pore size diameter. Standard deviation was less than $5 \%$ in all operative conditions.

Membrane porosity is strictly correlated with the membranes' morphology. All the membranes prepared with the casting solution composed of PVDF and TEP (M1-M3), exhibited a porosity near to or lower than $\sim 80 \%$, which is in accordance with the SEM images shown in Figure 3. On the contrary, by adding PVP and PEG to the dope solution, the resulting membrane presented a higher porosity, which further increased with the presence of GO, reaching a value of $\sim 87 \%$. However, a GO content of $0.5 \mathrm{wt} \%$ caused a reduction in porosity for M10, probably due to the blocking of pores by catalyst nanosheets' aggregation. The results of the tensile strength and elongation tests are shown in Table 5 . The Young's modulus for all of the membranes was improved when GO, together with PVP and PEG, was added to the dope solution in comparison to the analogue polymeric pristine PVDF membranes. These results could be explained in terms of GO's superior mechanical stability, high surface area and aspect ratio [40]. The positive effect of GO on the membrane mechanical features is confirmed by the elastic modulus of M10, for which a value of $\sim 45 \mathrm{~N} / \mathrm{mm}^{2}$ was detected. Elongation at break revealed high values for all the prepared membranes, with a maximum of 50\% for M8. However, for M9 and M10, a decline in membrane elongation was observed, probably due to GO aggregation at the point of breakage.

Table 5. Mechanical properties and porosity of the prepared membranes.

\begin{tabular}{cccc}
\hline \multirow{2}{*}{ Membrane } & Young's Modulus & Elongation at Break & Porosity \\
\cline { 2 - 4 } & $\mathbf{N} / \mathbf{m m}^{\mathbf{2}}$ & $\mathbf{E} \%$ & $\%$ \\
\hline M1 & $25.3 \pm 0.3$ & $27.2 \pm 3.6$ & $77.8 \pm 0.5$ \\
M2 & $21.5 \pm 0.5$ & $20.4 \pm 4.6$ & $78.4 \pm 0.4$ \\
M3 & $29.6 \pm 0.1$ & $40.5 \pm 1.3$ & $79.5 \pm 0.9$ \\
M4 & $18.7 \pm 3.4$ & $40.9 \pm 2.8$ & $83.5 \pm 0.8$ \\
M5 & $18.7 \pm 3.3$ & $22.5 \pm 1.3$ & $84.5 \pm 0.4$ \\
M6 & $14.4 \pm 2.2$ & $47.0 \pm 1.9$ & $82.8 \pm 0.2$ \\
M7 & $22.6 \pm 3.4$ & $30.8 \pm 1.1$ & $86.7 . \pm 0.4$ \\
M8 & $22.1 \pm 2.5$ & $50.3 \pm 2.4$ & $87.5 \pm 0.9$ \\
M9 & $23.2 \pm 3.9$ & $3.0 \pm 1.2$ & $86.4 \pm 0.4$ \\
M10 & $44.4 \pm 1.4$ & $2.4 \pm 1.3$ & $83.7 \pm 0.7$ \\
\hline
\end{tabular}

Carbon derivatives, due to their excellent mechanical properties, are the best additives for improving the mechanical strength of the membranes. A large number of functional groups on the GO nanosheets' surface can create a stable cross-linked network with the PVDF polymer. 
Hence, GO nanosheets can increase the mechanical properties of the membrane due to more favorable inherent properties.

\subsection{Photocatalytic Tests}

In order to evaluate the photocatalytic activity of M7-M10 membranes containing GO, the degradation of $\mathrm{MB}^{+}$under visible light was performed. Three different phenomena, which can occur during the experimental tests, can be responsible for the dye concentration decrease in the feed solution: the spontaneous degradation of $\mathrm{MB}^{+}$by light, adsorption of $\mathrm{MB}^{+}$by the membrane and effective degradation of $\mathrm{MB}^{+}$through the photocatalytic activity of GO.

In order to consider exclusively the dye degradation related to the catalyst activity, the impact of the first two phenomena (degradation by light and adsorption) was also evaluated. Dye solution degradation tests, in the absence of a membrane, were conducted by exposing the dye solution to visible light. A degradation of about $20 \%$ was observed under these conditions and it was considered as a base line (Figure 10). The dye removal related to an adsorption mechanism, and therefore not connected to the catalytic activity of GO, was considered by conditioning the membrane overnight in a $50 \mathrm{~mL}$ dye solution $(10 \mu \mathrm{mol} / \mathrm{L})$ before each test in order to reach an adsorption equilibrium. Moreover, photocatalytic tests with M4-M6 membranes (catalyst free) were performed under light irradiation, resulting in a removal of the dye of up to $52.6 \%$ (in case of M5), as shown in Figure 10 (this removal was exclusively due to adsorption mechanism and $\mathrm{MB}^{+}$spontaneous degradation under light irradiation). Tests carried out with M4-M6 membranes (catalysts free under visible light) allowed to discriminate the photocatalytic activity of the catalysts from other phenomena occurring during the tests.

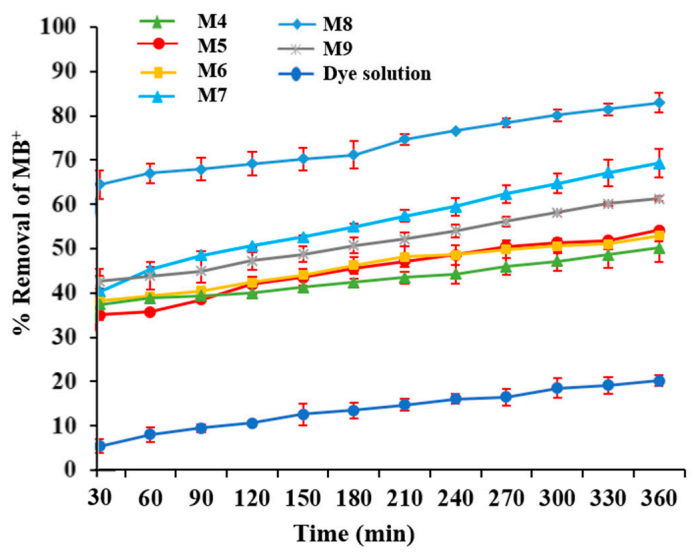

Figure 10. Comparison of dye removal using a catalyst-free (M4-M6) and GO-filled (M7-M9) membranes and dye solution degradation without a membrane under visible light irradiation.

As can be seen in Figure 10, all the membranes prepared with GO (M7-M9) presented higher $\mathrm{MB}^{+}$ degradation efficiency in comparison to the others as a consequence of the photocatalytic contribute of GO.

In particular, the photocatalytic M8 membrane showed the maximum degradation value of $83.3 \%$, followed by M7 (about $68 \%$ ) and M9 (about 62\%). The three membranes presented the same GO content $(0.125 \mathrm{wt} \%)$, and they only differed in their exposure to a humid environment (from 0 to $5 \mathrm{~min}$ ) during their preparation. The reason for their different catalytic behavior might be, therefore, related to their different membrane morphology. M7 presented a more compact and denser structure, as evidenced by SEM and by the lower PWP values, resulting in a decreased contact surface with the dye solution. A more spongy-like structure (like the case of M8 and M9 membranes) can offer, in fact, more contact sites between the catalyst and the dye, favoring its degradation. However, M9 membrane, which was the more porous and permeable membrane, exhibited the lowest degradation performance. 
This could be related to the formation of a too-loose structure, which did not favor the contact between the catalyst and the dye solution.

The effect of membrane morphology on dye degradation can also be observed in the results reported in Figure 11. In this graph, the removal efficiency of the membranes M5 (0 wt \% GO), M8 (0.125 wt \% GO) and M10 (0.5 wt \% GO), differing in formulation just in the GO content, is displayed. As can be seen from the graph, despite the higher concentration of GO, M10 membrane did not show the highest degradation rate. This could be due to its different morphology and pore size. In this case, in fact, the presence of GO in the polymer solution favored the formation of a membrane with higher pore size, as shown in Figure 9, which negatively affected the MB removal efficiency due to a lower contact of the membrane catalytic sites with the dye solution.

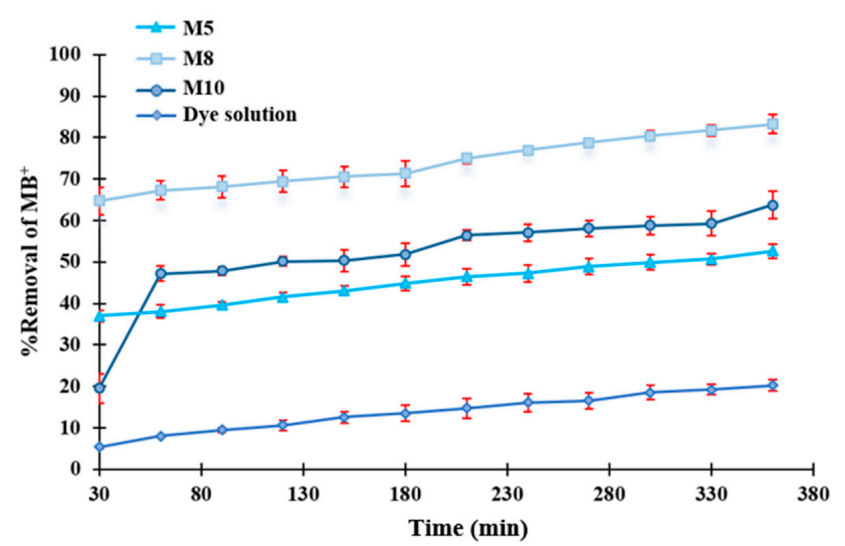

Figure 11. Dye removal using M5, M8 and M10 membranes and dye solution degradation without membrane under visible light irradiation.

The degradation of MB using GO, often anchored with various metal oxides, has been reported by many authors in the literature [72,73]. The $\mathrm{MB}^{+}$is degraded following a pathway which culminates with the total conversion of the dye in water, carbon dioxide and inorganic anions $\left(\mathrm{SO}_{4}{ }^{2-} ; \mathrm{NH}_{4}{ }^{+}\right.$and $\mathrm{NO}_{3}{ }^{-}$). Most of the time, the formation of a series of intermediates occurs $[74,75]$.

\subsection{Influence of $\mathrm{pH}$ on Removal Operation}

Since GO contains a large percentage of oxygen groups such as carboxylic acid $(\mathrm{COOH})$, ketone $(\mathrm{C}=\mathrm{O})$, hydroxide $(\mathrm{OH})$ and epoxy $(\mathrm{C}-\mathrm{O}), \mathrm{pH}$ plays a strong influence on its charge, therefore influencing its adsorption capacity by electrostatic interaction. The great adsorption capacity of GO is attributable to the negative charge of $\mathrm{COO}^{-}$groups and $\pi-\pi$ interaction with aromatic groups of adsorbent molecules. The zeta potential charge of the membrane, which is dependent on the $\mathrm{pH}$ of the solution, was measured by Malvern Zetasizer, exhibiting a change from positive to negative charges in $\mathrm{GO}$ at $\mathrm{pH}$ values around 4 . This is compatible with the protonation/deprotonation of the carboxylic acid groups present on $\mathrm{GO}$ as the main factor responsible for the charge present on the nanosheets.

Due to these changes in Coulombic charges and adsorption, the photocatalytic activity of the membranes is also strongly influenced by the solution $\mathrm{pH}$. Figure 12 displays the photodegradation of an $\mathrm{MB}^{+}$solution for the M8 membrane at different $\mathrm{pH}$ values (3, 7 and 9), adjusted using $0.2 \mathrm{M} \mathrm{NaOH}$ and $\mathrm{HCl}$. As can be seen, $\mathrm{MB}^{+}$degradation decreased in the acidic and basic conditions, reaching its maximum under a neutral $\mathrm{pH}$.

Degradation efficiency in acidic solution was significantly reduced, which could be rationalized by the occupation of active sites on the membrane by protons, resulting in a change in the Coulombic charge of the GO nanosheets and a change in its adsorption properties. Membrane surface charge below the point of zero charge $\left(\mathrm{pH}_{\mathrm{pzc}} \sim 6\right)$ is positive, and above that, value is negative and, as mentioned before, $\mathrm{MB}^{+}$is a cationic dye because of the amine group. Therefore, for the dye solution with $\mathrm{pH}$ values of less than $\mathrm{pH}_{\mathrm{pzc}}$, electrostatic repulsion resulted in a dramatic decrease in degradation efficiency. 


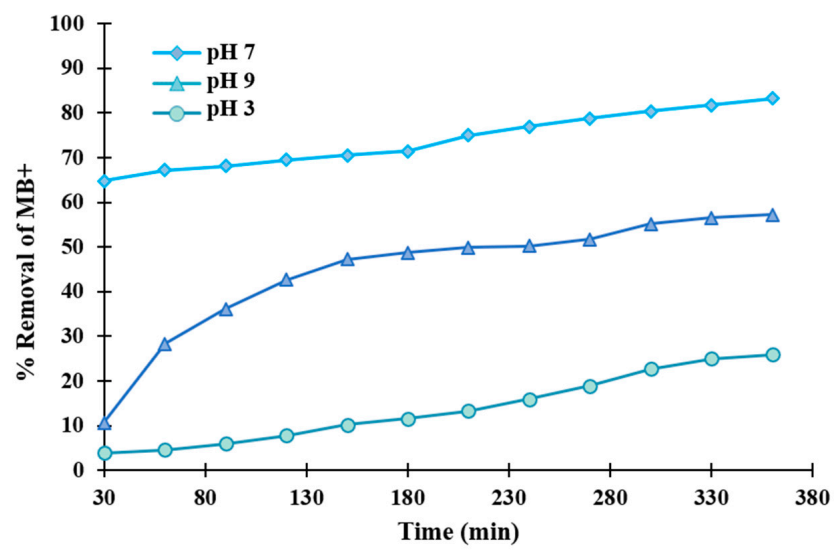

Figure 12. Influence of the $\mathrm{pH}$ of the dye solution on removal efficiency in M8 membrane.

At quasi-neutral $\mathrm{pH}$ values, the formation of a complex between basic groups of $\mathrm{GO}$ (beyond $\mathrm{pH}$ 6) and cationic dye molecules by electrostatic attraction should favor adsorption on the GO nanosheets and, therefore, also promote photocatalytic degradation. A further increase in $\mathrm{pH}$ to strongly basic values should again disfavor the adsorption of $\mathrm{MB}^{+}$on $\mathrm{GO}$ by competition with the high concentration of counter cations present in the solution, resulting again in a lower photocatalytic activity.

\subsection{Salt Effect Assessment in Dye Removal Efficiency}

In order to investigate the influence of salt presence on the removal process, dye solutions containing 0.001 and $0.01 \mathrm{~mol} / \mathrm{L}$ of $\mathrm{NaCl}$ were tested with the $\mathrm{M} 8$ membrane and the results are shown in Figure 13. As can be seen from the graph, the presence of $\mathrm{NaCl}$ caused a decrease in membrane removal efficiency, which was particularly evidenced at a high salt content $(0.01 \mathrm{M})$. Chloride ions in the solution formed a stable complex with $\mathrm{MB}^{+}$and, therefore, $\mathrm{MB}^{+}$was involved in a competition between adsorption on the membrane and pairing with chloride ions [76]. The competition of the dye for a complex formation at stronger ion strengths (higher salt concentrations) was increased, which resulted in a lower availability of the dye for the photocatalytic membrane sites and, therefore, a lesser degradation efficiency. On the other hand, as a consequence of this competition, the number of $\mathrm{MB}^{+}$ molecules adsorbed on the membrane surface was decreased and the photocatalytic capacity of the membrane was compromised. The decrease in process efficiency as a consequence of $\mathrm{Cl}^{-}$anions presence is in agreement with the literature data $[77,78]$. The decrease in removal efficiency might be, in fact, related to $\mathrm{Cl}^{-}$ions in the dye solution which decreased the electrostatic attraction between $\mathrm{MB}^{+}$ and the active sites of the membrane (screening effect) [79].

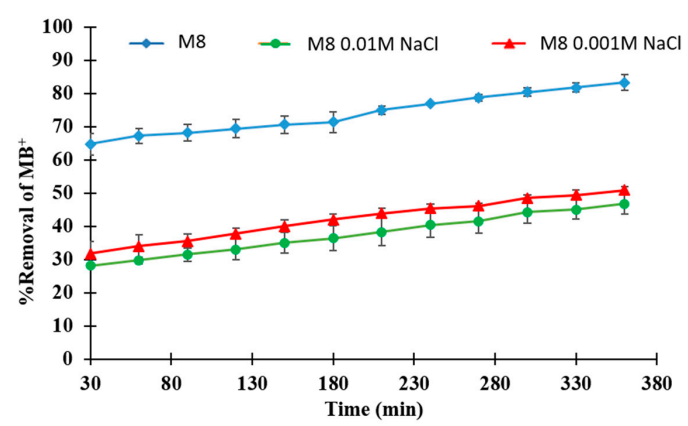

Figure 13. Effect of salty dye solutions $(0.001$ and $0.01 \mathrm{M} \mathrm{NaCl})$ on the removal process for $\mathrm{M} 8$ membrane.

\section{Conclusions}

In this work, four types of membranes were prepared by using a non-toxic solvent and, for the first time, GO nanosheets were used as a metal-free catalyst to photoactivate the membrane under 
simulated solar light (visible light) irradiation. The influence of exposure time $(0,2.5$ and $5 \mathrm{~min})$ of the membrane to a humid environment before coagulation in a non-solvent bath was investigated for three sets of membranes prepared with polymer and solvent, with the addition of pore-forming additives and with the addition of the photocatalyst GO. The concentration of GO in the membrane was also varied. The membrane structure changed from a dense and compact morphology in the absence of PVP and PEG as additives to a finger-like architecture in presence of the pore formers. In the latter case, the increase in membrane exposure time to humidity enhanced the formation of a sponge-like structure. This structure was further promoted by the addition of GO. The addition of pore-forming agents and GO also led to an increase in the roughness, in particular for higher GO concentration.

The incorporation of GO significantly improved the mechanical strength of the obtained membranes as well as their wettability, due to the large number of hydroxyl groups on the layer surface. The development of a hydration layer on the membrane surface can decrease the attachment of pollutants and microorganisms, protein and pharmaceutical foulants, making the membrane less prone to fouling onset.

M8, prepared with PVP, PEG and GO $(0.125 \mathrm{wt} \%)$ in the dope solution, and exposed for $2.5 \mathrm{~min}$ to moisture during the VIPS step, exhibited good photocatalytic performance towards $\mathrm{MB}^{+}$dye, used as a model pollutant under simulated solar light irradiation, reaching a dye removal efficiency of $83.5 \%$.

Photocatalytic experiments with $\mathrm{pH}$ values of 3,7 and 9 were performed, showing that quasi-neutral $\mathrm{pH}$ is an optimum value for the photocatalytic process. The presence of salt $(\mathrm{NaCl})$ negatively affected the photocatalytic process, causing a decrease in the dye degradation efficiency, probably related to $\mathrm{Cl}^{-}$ions in the dye solution which decreased the electrostatic attraction between $\mathrm{MB}^{+}$and the active sites of the membrane.

Overall, the present results show that by using environmentally greener solvents and procedures, it is possible to prepare functional PVDF membranes that exhibit good photocatalytic activity employing $\mathrm{GO}$ as a catalyst. This functionality should allow for the development of more efficient membranes using less toxic solvents.

Supplementary Materials: The following are available online at http://www.mdpi.com/2073-4360/12/7/1509/s1, Materials and Methods for GO and membrane characterization; Figure S1: XPS survey of the two GO samples. The peaks corresponding to C1s and O1s appear in the high resolution XPS between 283 and 290 and 536 and $539 \mathrm{eV}$, respectively. For the high resolution C1s peak see Figure 2d; Figure S2: Raman spectrum of GO; Figure S3: CA pictures of M1 $(a, b)$ and M7 $(c, d)$ membranes. Top surface $(a, c)$, bottom surface $(b, d)$.

Author Contributions: Conceptualization, T.M., H.G. and A.F.; Data curation, H.G. and A.F.; Investigation, S.A., T.M., F.G., C.U. and M.P.; Methodology, T.M., J.B.P., F.G., C.U. and A.F.; Supervision, A.F.; Validation, T.M., F.G., C.U., H.G. and A.F.; Writing-original draft, S.A., T.M. and H.G.; Writing-review and editing, T.M., F.G., C.U. and A.F. All authors have read and agreed to the published version of the manuscript.

Funding: This research received no external funding.

Acknowledgments: The authors acknowledge the financial support from Iran Science Ministry. The authors also sincerely thank the Institute on Membrane Technology, National Research Council of Italy (ITM-CNR) for kindly collaborate.

Conflicts of Interest: The authors declare no competing financial interest.

\section{References}

1. Deowan, S.A.; Galiano, F.; Hoinkis, J.; Johnson, D.; Altinkaya, S.A.; Gabriele, B.; Hilal, N.; Drioli, E.; Figoli, A. Novel low-fouling membrane bioreactor (MBR) for industrial wastewater treatment. J. Memb. Sci. 2016, 510, 524-532. [CrossRef]

2. Figoli, A.; Ursino, C.; Galiano, F.; Di Nicolò, E.; Campanelli, P.; Carnevale, M.C.; Criscuoli, A. Innovative hydrophobic coating of perfluoropolyether (PFPE) on commercial hydrophilic membranes for DCMD application. J. Memb. Sci. 2017, 522, 192-201. [CrossRef]

3. Dao, V.-D.; Vu, N.H.; Choi, H.-S. All day Limnobium laevigatum inspired nanogenerator self-driven via water evaporation. J. Power Sources 2020, 448, 227388. [CrossRef]

4. Dao, V.-D.; Vu, N.H.; Yun, S. Recent advances and challenges for solar-driven water evaporation system toward applications. Nano Energy 2020, 68, 104324. [CrossRef] 
5. Dao, V.-D.; Choi, H.-S. Carbon-Based Sunlight Absorbers in Solar-Driven Steam Generation Devices. Glob. Challenges 2018, 2, 1700094. [CrossRef]

6. Pastrana-Martínez, L.M.; Morales-Torres, S.; Figueiredo, J.L.; Faria, J.L.; Silva, A.M.T. Graphene oxide based ultrafiltration membranes for photocatalytic degradation of organic pollutants in salty water. Water Res. 2015, 77, 179-190. [CrossRef]

7. Zhang, X.; Wang, D.K.; Diniz Da Costa, J.C. Recent progresses on fabrication of photocatalytic membranes for water treatment. Catal. Today 2014, 230, 47-54. [CrossRef]

8. Athanasekou, C.P.; Moustakas, N.G.; Morales-Torres, S.; Pastrana-Martínez, L.M.; Figueiredo, J.L.; Faria, J.L.; Silva, A.M.T.; Dona-Rodriguez, J.M.; Romanos, G.E.; Falaras, P. Ceramic photocatalytic membranes for water filtration under UV and visible light. Appl. Catal. B Environ. 2015, 178, 12-19. [CrossRef]

9. Athanasekou, C.P.; Romanos, G.E.; Katsaros, F.K.; Kordatos, K.; Likodimos, V.; Falaras, P. Very efficient composite titania membranes in Hybrid ultrafiltration/photocatalysis water treatment processes. J. Memb. Sci. 2012, 392-393, 192-203. [CrossRef]

10. Romanos, G.E.; Athanasekou, C.P.; Katsaros, F.K.; Kanellopoulos, N.K.; Dionysiou, D.D.; Likodimos, V.; Falaras, P. Double-side active $\mathrm{TiO}_{2}$-modified nanofiltration membranes in continuous flow photocatalytic reactors for effective water purification. J. Hazard. Mater. 2012, 211-212, 304-316. [CrossRef]

11. Zhang, W.; Dong, F.; Xiong, T.; Zhang, Q. Synthesis of BiOBr-graphene and BiOBr-graphene oxide nanocomposites with enhanced visible light photocatalytic performance. Ceram. Int. 2014, 40, 9003-9008. [CrossRef]

12. Dadvar, E.; Kalantary, R.R.; Ahmad Panahi, H.; Peyravi, M. Efficiency of Polymeric Membrane Graphene Oxide- $\mathrm{TiO}_{2}$ for Removal of Azo Dye. J. Chem. 2017, 2017, 1-13. [CrossRef]

13. Simone, S.; Galiano, F.; Faccini, M.; Boerrigter, M.; Chaumette, C.; Drioli, E.; Figoli, A. Preparation and Characterization of Polymeric-Hybrid $\mathrm{PES} / \mathrm{TiO}_{2}$ Hollow Fiber Membranes for Potential Applications in Water Treatment. Fibers 2017, 5, 14. [CrossRef]

14. Liu, G.; Han, K.; Ye, H.; Zhu, C.; Gao, Y.; Liu, Y.; Zhou, Y. Graphene oxide/triethanolamine modified titanate nanowires as photocatalytic membrane for water treatment. Chem. Eng. J. 2017, 320, 74-80. [CrossRef]

15. Djafer, L.; Ayral, A.; Ouagued, A. Robust synthesis and performance of a titania-based ultrafiltration membrane with photocatalytic properties. Sep. Purif. Technol. 2010, 75, 198-203. [CrossRef]

16. Jung, J.T.; Lee, W.H.; Kim, J.O. Photodegradation and permeability of conventional photocatalytic reactor and two different submerged membrane photocatalytic reactors for the removal of humic acid in water. Desalin. Water Treat. 2016, 57, 26765-26772. [CrossRef]

17. Xu, Z.; Wu, T.; Shi, J.; Teng, K.; Wang, W.; Ma, M.; Li, J.; Qian, X.; Li, C.; Fan, J. Photocatalytic antifouling PVDF ultrafiltration membranes based on synergy of graphene oxide and $\mathrm{TiO}_{2}$ for water treatment. J. Memb. Sci. 2016, 520, 281-293. [CrossRef]

18. Gao, Y.; $\mathrm{Hu}, \mathrm{M} . ; \mathrm{Mi}, \mathrm{B}$. Membrane surface modification with $\mathrm{TiO}_{2}$-graphene oxide for enhanced photocatalytic performance. J. Memb. Sci. 2014, 455, 349-356. [CrossRef]

19. Zhao, H.; Chen, S.; Quan, X.; Yu, H.; Zhao, H. Integration of microfiltration and visible-light-driven photocatalysis on g-C3N4 nanosheet/reduced graphene oxide membrane for enhanced water treatment. Appl. Catal. B Environ. 2016, 194, 134-140. [CrossRef]

20. Cruz-Ortiz, B.R.; Hamilton, J.W.J.; Pablos, C.; Díaz-Jiménez, L.; Cortés-Hernández, D.A.; Sharma, P.K.; Castro-Alférez, M.; Fernández-Ibañez, P.; Dunlop, P.S.M.; Byrne, J.A. Mechanism of photocatalytic disinfection using titania-graphene composites under UV and visible irradiation. Chem. Eng. J. 2017, 316, 179-186. [CrossRef]

21. Galiano, F.; Song, X.; Marino, T.; Boerrigter, M.; Saoncella, O.; Simone, S.; Faccini, M.; Chaumette, C.; Drioli, E.; Figoli, A. Novel Photocatalytic PVDF/Nano-TiO 2 Hollow Fibers for Environmental Remediation. Polymers 2018, 10, 1134. [CrossRef]

22. Szymański, K.; Morawski, A.W.; Mozia, S. Humic acids removal in a photocatalytic membrane reactor with a ceramic UF membrane. Chem. Eng. J. 2016, 305, 19-27. [CrossRef]

23. Mozia, S.; Morawski, A.W.; Molinari, R.; Palmisano, L.; Loddo, V. Photocatalytic Membrane Reactors: Fundamentals, Membrane Materials and Operational Issues; Woodhead Publishing Limited: Sawston, UK, 2013; ISBN 9780857094155.

24. Marino, T.; Blefari, S.; Di Nicolò, E.; Figoli, A. A more sustainable membrane preparation using triethyl phosphate as solvent. Green Process. Synth. 2017, 6, 295-300. [CrossRef] 
25. Benhabiles, O.; Galiano, F.; Marino, T.; Mahmoudi, H.; Lounici, H.; Figoli, A. Preparation and Characterization of $\mathrm{TiO}_{2}$-PVDF/PMMA Blend Membranes Using an Alternative Non-Toxic Solvent for UF/MF and Photocatalytic Application. Molecules 2019, 24, 724. [CrossRef]

26. Marino, T.; Russo, F.; Figoli, A. The Formation of Polyvinylidene Fluoride Membranes with Tailored Properties via Vapour/Non-Solvent Induced Phase Separation. Membranes 2018, 8, 71. [CrossRef] [PubMed]

27. Li, X.; Wang, J.; Hu, Z.; Li, M.; Ogino, K. In situ polypyrrole polymerization enhances the photocatalytic activity of nanofibrous $\mathrm{TiO}_{2} / \mathrm{SiO}_{2}$ membranes. Chinese Chem. Lett. 2018, 29, 166-170. [CrossRef]

28. Liu, Z.; Miao, Y.E.; Liu, M.; Ding, Q.; Tjiu, W.W.; Cui, X.; Liu, T. Flexible polyaniline-coated $\mathrm{TiO}_{2} / \mathrm{SiO}_{2}$ nanofiber membranes with enhanced visible-light photocatalytic degradation performance. J. Colloid Interface Sci. 2014, 424, 49-55. [CrossRef]

29. Athanasekou, C.P.; Morales-Torres, S.; Likodimos, V.; Romanos, G.E.; Pastrana-Martinez, L.M.; Falaras, P.; Faria, J.L.; Figueiredo, J.L.; Silva, A.M.T. Prototype composite membranes of partially reduced graphene oxide/ $\mathrm{TiO}_{2}$ for photocatalytic ultrafiltration water treatment under visible light. Appl. Catal. B Environ. 2014, 158-159, 361-372. [CrossRef]

30. Rao, G.; Zhang, Q.; Zhao, H.; Chen, J.; Li, Y. Novel titanium dioxide/iron (III) oxide/graphene oxide photocatalytic membrane for enhanced humic acid removal from water. Chem. Eng. J. 2016, 302, 633-640. [CrossRef]

31. Chen, W.; Ye, T.; Xu, H.; Chen, T.; Geng, N.; Gao, X. An ultrafiltration membrane with enhanced photocatalytic performance from grafted $\mathrm{N}-\mathrm{TiO}_{2}$ /graphene oxide. RSC Adv. 2017, 7, 9880-9887. [CrossRef]

32. Bellobono, I.R.; Bonardi, M.; Castellano, L.; Selli, E.; Righetto, L. Degradation of some chloro-aliphatic water contaminants by photocatalytic membranes immobilizing titanium dioxide. J. Photochem. Photobiol. A Chem. 1992, 67, 109-115. [CrossRef]

33. Shao, F.; Xu, C.; Ji, W.; Dong, H.; Sun, Q.; Yu, L.; Dong, L. Layer-by-layer self-assembly $\mathrm{TiO}_{2}$ and graphene oxide on polyamide reverse osmosis membranes with improved membrane durability. Desalination 2017, 423, 21-29. [CrossRef]

34. Chen, R.; Liu, H. Preparation of $\mathrm{Cr}$-doped $\mathrm{TiO}_{2} / \mathrm{SiO}_{2}$ photocatalysts and their photocatalytic properties. J. Chin. Chem. Soc. 2011, 58, 947-954. [CrossRef]

35. Marino, T.; Boerrigter, M.; Faccini, M.; Chaumette, C.; Arockiasamy, L.; Bundschuh, J.; Figoli, A. Photocatalytic activity and synthesis procedures of $\mathrm{TiO}_{2}$ nanoparticles for potential applications in membranes. In Application of Nanotechnology in Membranes for Water Treatment; Figoli, A., Hoinkis, J., Altinkaya, S.A., Bundschuh, J., Eds.; CRC Press: Boca Raton, FL, USA, 2017.

36. Morris, R.E.; Krikanova, E.; Shadman, F. Photocatalytic membrane for removal of organic contaminants during ultra-purification of water. Clean Technol. Environ. Policy 2004, 6, 96-104. [CrossRef]

37. Lopez, L.C.; Buonomenna, M.G.; Fontananova, E.; Iacoviello, G.; Drioli, E.; D’Agostino, R.; Favia, P. A New Generation of Catalytic Poly(vinylidene fluoride) Membranes: Coupling Plasma Treatment with Chemical Immobilization of Tungsten-Based Catalysts. Adv. Funct. Mater. 2006, 16, 1417-1424. [CrossRef]

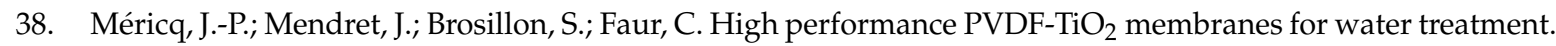
Chem. Eng. Sci. 2015, 123, 283-291. [CrossRef]

39. Safarpour, M.; Vatanpour, V.; Khataee, A. Preparation and characterization of graphene oxide/ $\mathrm{TiO}_{2}$ blended PES nanofiltration membrane with improved antifouling and separation performance. Desalination 2016, 393, 65-78. [CrossRef]

40. Wang, Z.; Yu, H.; Xia, J.; Zhang, F.; Li, F.; Xia, Y.; Li, Y. Novel GO-blended PVDF ultrafiltration membranes. Desalination 2012, 299, 50-54. [CrossRef]

41. Chai, P.V.; Mahmoudi, E.; Teow, Y.H.; Mohammad, A.W. Preparation of novel polysulfone- $\mathrm{Fe}_{3} \mathrm{O}_{4} / \mathrm{GO}$ mixed-matrix membrane for humic acid rejection. J. Water Process Eng. 2015, 15, 83-88. [CrossRef]

42. Mahlambi, M.M.; Vilakati, G.D.; Mamba, B.B. Synthesis, Characterization, and Visible Light Degradation of Rhodamine B Dye by Carbon-Covered Alumina Supported Pd- $\mathrm{TiO}_{2} /$ Polysulfone Membranes. Sep. Sci. Technol. 2014, 49, 2124-2134. [CrossRef]

43. Ma, S.; Meng, J.; Li, J.; Zhang, Y.; Ni, L. Synthesis of catalytic polypropylene membranes enabling visible-light-driven photocatalytic degradation of dyes in water. J. Memb. Sci. 2014, 453, 221-229. [CrossRef]

44. Moslehyani, A.; Ismail, A.F.; Othman, M.H.D.; Matsuura, T. Design and performance study of hybrid photocatalytic reactor-PVDF/MWCNT nanocomposite membrane system for treatment of petroleum re fi nery wastewater. DES 2015, 363, 99-111. [CrossRef] 
45. Kumar, M.; Gholamvand, Z.; Morrissey, A.; Nolan, K.; Ulbricht, M.; Lawler, J. Preparation and characterization of low fouling novel hybrid ultrafiltration membranes based on the blends of $\mathrm{GO}-\mathrm{TiO}_{2}$ nanocomposite and polysulfone for humic acid removal. J. Memb. Sci. 2016, 506, 38-49. [CrossRef]

46. Zhang, X.; Lang, W.Z.; Yan, X.; Lou, Z.Y.; Chen, X.F. Influences of the structure parameters of multi-walled carbon nanotubes(MWNTs) on PVDF/PFSA/O-MWNTs hollow fiber ultrafiltration membranes. J. Memb. Sci. 2016, 499, 179-190. [CrossRef]

47. Castro-Muñoz, R.; Galiano, F.; de la Iglesia, Ó.; Fíla, V.; Téllez, C.; Coronas, J.; Figoli, A. Graphene oxide-Filled polyimide membranes in pervaporative separation of azeotropic methanol-MTBE mixtures. Sep. Purif. Technol. 2019, 224, 265-272. [CrossRef]

48. Grasso, G.; Galiano, F.; Yoo, M.J.; Mancuso, R.; Park, H.B.; Gabriele, B.; Figoli, A.; Drioli, E. Development of graphene-PVDF composite membranes for membrane distillation. J. Memb. Sci. 2020, 604, 118017. [CrossRef]

49. Yao, Y.; Miao, S.; Yu, S.; Ping Ma, L.; Sun, H.; Wang, S. Fabrication of $\mathrm{Fe}_{3} \mathrm{O}_{4} / \mathrm{SiO}_{2}$ core/shell nanoparticles attached to graphene oxide and its use as an adsorbent. J. Colloid Interface Sci. 2012, 379, 20-26. [CrossRef] [PubMed]

50. Zhang, X.; Cheng, C.; Zhao, J.; Ma, L.; Sun, S.; Zhao, C. Polyethersulfone enwrapped graphene oxide porous particles for water treatment. Chem. Eng. J. 2013, 215-216, 72-81. [CrossRef]

51. Marcano, D.C.; Kosynkin, D.V.; Berlin, J.M.; Sinitskii, A.; Sun, Z.Z.; Slesarev, A.; Alemany, L.B.; Lu, W.; Tour, J.M. Improved Synthesis of Graphene Oxide. ACS Nano 2010, 4, 4806-4814. [CrossRef]

52. Geim, A.K.; Novoselov, K.S. The rise of graphene. Nat. Mater. 2007, 6, 183-191. [CrossRef]

53. Krishnamoorthy, K.; Mohan, R.; Kim, S.J. Graphene oxide as a photocatalytic material. Appl. Phys. Lett. 2011, 98, 2009-2012. [CrossRef]

54. Hou, W.C.; Wang, Y.S. Photocatalytic Generation of $\mathrm{H}_{2} \mathrm{O}_{2}$ by Graphene Oxide in Organic Electron Donor-Free Condition under Sunlight. ACS Sustain. Chem. Eng. 2017, 5, 2994-3001. [CrossRef]

55. Stankovich, S.; Dikin, D.A.; Piner, R.D.; Kohlhaas, K.A.; Kleinhammes, A.; Jia, Y.; Wu, Y.; Nguyen, S.B.T.; Ruoff, R.S. Synthesis of graphene-based nanosheets via chemical reduction of exfoliated graphite oxide. Carbon N. Y. 2007, 45, 1558-1565. [CrossRef]

56. Baker, R.W. Membrane Technology and Applications; John Wiley \& Sons: New York, NY, USA, 2004; ISBN 0470854456.

57. Li, S.; Cui, Z.; Zhang, L.; He, B.; Li, J. The effect of sulfonated polysulfone on the compatibility and structure of polyethersulfone-based blend membranes. J. Memb. Sci. 2016, 513, 1-11. [CrossRef]

58. Tseng, H.-H.; Zhuang, G.-L.; Su, Y.-C. The effect of blending ratio on the compatibility, morphology, thermal behavior and pure water permeation of asymmetric CAP/PVDF membranes. Desalination 2012, 284, 269-278. [CrossRef]

59. Rehan, Z.; Gzara, L.; Khan, S.; Alamry, K.; El-Shahawi, M.S.; Albeirutty, M.; Figoli, A.; Drioli, E.; Asiri, A. Synthesis and Characterization of Silver Nanoparticles-Filled Polyethersulfone Membranes for Antibacterial and Anti-Biofouling Application. Recent Pat. Nanotechnol. 2016, 10, 231-251. [CrossRef] [PubMed]

60. Mousavi, S.M.; Zadhoush, A. Investigation of the relation between viscoelastic properties of polysulfone solutions, phase inversion process and membrane morphology: The effect of solvent power. J. Memb. Sci. 2017, 532, 47-57. [CrossRef]

61. Wongchitphimon, S.; Wang, R.; Jiraratananon, R.; Shi, L.; Loh, C.H. Effect of polyethylene glycol (PEG) as an additive on the fabrication of polyvinylidene fluoride-co-hexafluropropylene (PVDF-HFP) asymmetric microporous hollow fiber membranes. J. Memb. Sci. 2011, 369, 329-338. [CrossRef]

62. Russo, F.; Galiano, F.; Pedace, F.; Aricò, F.; Figoli, A. Dimethyl Isosorbide as a Green Solvent for Sustainable Ultrafiltration and Microfiltration Membrane Preparation. ACS Sustain. Chem. Eng. 2020, 8, 659-668. [CrossRef]

63. Russo, F.; Castro-Muñoz, R.; Galiano, F.; Figoli, A. Unprecedented preparation of porous Matrimid ${ }^{\circledR} 5218$ membranes. J. Memb. Sci. 2019, 585, 166-174. [CrossRef]

64. Marino, T.; Galiano, F.; Simone, S.; Figoli, A. DMSO EVOL ${ }^{\mathrm{TM}}$ as novel non-toxic solvent for polyethersulfone membrane preparation. Environ. Sci. Pollut. Res. 2019, 26, 14774-14785. [CrossRef] [PubMed]

65. Bui, V.-T.; Dao, V.-D.; Choi, H.-S. Transferable thin films with sponge-like porous structure via improved phase separation. Polymer 2016, 101, 184-191. [CrossRef] 
66. Meng, N.; Priestley, R.C.E.; Zhang, Y.; Wang, H.; Zhang, X. The effect of reduction degree of GO nanosheets on microstructure and performance of PVDF/GO hybrid membranes. J. Memb. Sci. 2016, 501, 169-178. [CrossRef]

67. Xie, Q.; Xu, J.; Feng, L.; Jiang, L.; Tang, W.; Luo, X.; Han, C.C. Facile Creation of a Super-Amphiphobic Coating Surface with Bionic Microstructure. Adv. Mater. 2004, 16, 302-305. [CrossRef]

68. Razmjou, A.; Arifin, E.; Dong, G.; Mansouri, J.; Chen, V. Superhydrophobic modification of $\mathrm{TiO}_{2}$ nanocomposite PVDF membranes for applications in membrane distillation. J. Memb. Sci. 2012, 415-416, 850-863. [CrossRef]

69. Teow, Y.H.; Ooi, B.S.; Ahmad, A.L. Fouling behaviours of $\mathrm{PVDF}^{-T i O}{ }_{2}$ mixed-matrix membrane applied to humic acid treatment. J. Water Process Eng. 2017, 15, 89-98. [CrossRef]

70. Wenzel, R.N. Resistance of solid surfaces to wetting by water. Ind. Eng. Chem. 1936, 28, 988-994. [CrossRef]

71. Zhu, Z.; Wang, L.; Xu, Y.; Li, Q.; Jiang, J.; Wang, X. Preparation and characteristics of graphene oxide-blending PVDF nanohybrid membranes and their applications for hazardous dye adsorption and rejection. J. Colloid Interface Sci. 2017, 504, 429-439. [CrossRef]

72. Liu, Y.; Jin, W.; Zhao, Y.; Zhang, G.; Zhang, W. Enhanced catalytic degradation of methylene blue by $\alpha-\mathrm{Fe}_{2} \mathrm{O}_{3}$ /graphene oxide via heterogeneous photo-Fenton reactions. Appl. Catal. B Environ. 2017, 206, 642-652. [CrossRef]

73. Qin, J.; Zhang, X.; Yang, C.; Cao, M.; Ma, M.; Liu, R. ZnO microspheres-reduced graphene oxide nanocomposite for photocatalytic degradation of methylene blue dye. Appl. Surf. Sci. 2017, 392, 196-203. [CrossRef]

74. Oliveira, L.C.A.; Gonçalves, M.; Guerreiro, M.C.; Ramalho, T.C.; Fabris, J.D.; Pereira, M.C.; Sapag, K. A new catalyst material based on niobia/iron oxide composite on the oxidation of organic contaminants in water via heterogeneous Fenton mechanisms. Appl. Catal. A Gen. 2007, 316, 117-124. [CrossRef]

75. Houas, A. Photocatalytic degradation pathway of methylene blue in water. Appl. Catal. B Environ. 2001, 31, 145-157. [CrossRef]

76. Kamble, S.P.; Mangrulkar, P.A.; Bansiwal, A.K.; Rayalu, S.S. Adsorption of phenol and o-chlorophenol on surface altered fly ash based molecular sieves. Chem. Eng. J. 2008, 138, 73-83. [CrossRef]

77. Sirtori, C.; Agüera, A.; Gernjak, W.; Malato, S. Effect of water-matrix composition on Trimethoprim solar photodegradation kinetics and pathways. Water Res. 2010, 44, 2735-2744. [CrossRef]

78. Yap, P.S.; Lim, T.T. Effect of aqueous matrix species on synergistic removal of bisphenol-A under solar irradiation using nitrogen-doped $\mathrm{TiO}_{2} / \mathrm{AC}$ composite. Appl. Catal. B Environ. 2011, 101, 709-717. [CrossRef]

79. Stuart, M.A.C.; Fleer, G.J.; Lyklema, J.; Norde, W.; Scheutjens, J.M.H.M. Adsorption of Ions, Polyelectrolytes and Proteins. Adv. Colloid Interface Sci. 1991, 34, 477-535. [CrossRef] 